\title{
The lived experience of drivers with a spinal cord injury: A qualitative inquiry
}

\author{
Lucia Mtetwa, B Sc (Hons) University of Zimbabwe \\ Masters Student, University of Stellenbosch
}

\section{Sherrilene Classen, BA OT (UFS), PhD OT (Nova Eastern University), MPH Epidemiology (University of Florida. Post-Doctoral Fellow, Public Health/Rehabilitation Sciences, University of Florida}

Lana van Niekerk, B OT (UFS), M OT (UFS), PhD OT (UCT)

Head, Division of Occupational Therapy, Department of Interdisciplinary Health Sciences, Stellenbosch University

Introduction: Driving is an instrumental activity of daily living and a facilitator of meaningful participation in society for the majority of the population, including persons with spinal cord injuries. Persons with spinal cord injury may have impaired fitness to drive capabilities. Little is known about perceptions of drivers with spinal cord injury on driving, driver rehabilitation, or return to driving. This study examined the post spinal cord injury driving experiences of drivers and illuminates their rehabilitation and return-to-driving needs within the South African context.

Method: This phenomenological study explored personal experiences of fourteen drivers with spinal cord injury, recruited through purposive sampling. Face-to-face, semi-structured interviews were audio recorded and transcribed verbatim. The data analysis was an inductive and iterative process.

Results/findings: Six themes represent the study findings: adjusting to physical limitations, safety perceptions and influencing factors, the positive role of driving, contextual features and supports, environmental barriers, and inconsistent provision of rehabilitation services. Conclusions: The findings indicated that occupational therapists ought to consider incorporating driver rehabilitation services and adopt mediation approaches to advocate for persons with spinal cord injury, who want to drive. Plausible practice and research opportunities are discussed for occupational therapists who are interested in driving and spinal cord injury.

Keywords: Driving, spinal cord injury, individual perspective, driver rehabilitation

\section{BACKGROUND AND LITERATURE REVIEW}

Driving is an instrumental activity of daily living (IADL) and a facilitator to meaningful participation in society for the majority of the population, including persons with spinal cord injuries $(\mathrm{SCl})$. Driving encompasses the execution of visual, perceptual, cognitive, and physical' (motor and sensory) skills within a complex environment. A SCl refers to damage to the spinal cord causing temporary or permanent limitations in motor, sensory or autonomic functions ${ }^{2}$. Based on the International Classification of Functioning, Disability and Health (ICF) ${ }^{3}$, an $\mathrm{SCl}$ affects the body structure, functions, and activities of daily living including driving - all which are critical for functioning and participation in daily life. Persons with an $\mathrm{SCl}$ may have impaired fitness to drive capabilities. Fitness to drive refers to "having the necessary mental and physical abilities and resources required for driving a motor vehicle safely and without unduly hindering the progress of other traffic" $4: 151$

\section{Driving as an instrumental activity of daily living}

For persons with $\mathrm{SCl}$, independence in mobility is essential as public transportation is not readily accessible, available or affordable. On the other hand, public transport systems established specifically for persons with mobility impairment are often inadequate, expensive, or inconvenient. For instance in South Africa the Dial-a-ride system is in place for people with mobility impairment, however it requires booking in advance and is therefore not flexible, convenient, and may not cater for emergency trips. Moreover, the service is only available in certain parts of the country (e.g. Durban, Cape Town and Johannesburg) and not in others.

The ability to drive one's own vehicle is associated with satisfac- tion, independence, engagement in daily activities ${ }^{5}$, autonomy ${ }^{6}$, role fulfilment $^{7}$, ability to pursue leisure activities ${ }^{8}$, and being employed ${ }^{9}$. In their study, Kiyono et al, ${ }^{9}$ discovered that $84 \%$ of their participants with traumatic complete tetraplegia who had jobs were able to drive independently, and that $70 \%$ of those who were able to drive independently had a job. On the other hand, only a minority of the study participants who could not drive were employed. The same study revealed that the participants who could not drive also did not participate in sporting activities; while half of those who could drive independently participated in some sporting activities ${ }^{9}$. They concluded that the ability to drive can enable engagement in social activities which may in turn enhance quality of life? de Faria ${ }^{10}$ conducted a study in Brazil and noted that the quest for independence and autonomy, the desire to engage in out of home activities, to work, to study as well as to access recreational places of choice, were the reasons for desiring to own an adapted car. Consistent with the older driver cessation literature ${ }^{11,12}$, persons with $\mathrm{SCl}$ who do not drive, or who give up driving post injury may also experience a decrease in "out of home" activities, loneliness, isolation, and depression.

\section{Driving with spinal cord injury}

Following $\mathrm{SCl}$, individuals experience challenges including fatigue, increased workload, and prolonged reaction time ${ }^{13}$. Due to the nature of impairments resultant from a SCl (e.g. impaired hand function, lower extremity paralysis), fitness to drive may be affected at the operational (e.g. lane keeping ${ }^{14}$ ) and tactical levels (e.g. overtaking $\left.{ }^{13}\right)$.

Peters ${ }^{13}$ explored the workload experiences of drivers with $\mathrm{SCl}$. He compared driving performance and workload of 26 tetraplegic 
drivers to a control group of 26 able-bodied drivers, using a driving simulator $^{13}$. Tetraplegic drivers used two types of hand controls while the control group used conventional controls. The study revealed that drivers with tetraplegia experienced a considerably greater time pressure and used more effort compared to able bodied drivers. They also became more exhausted from braking and accelerating ${ }^{14}$.

For quadriplegic drivers, limited hand function may further contribute to prolonged reaction time. Peters discovered that drivers with tetraplegia were able to drive as well as able bodied drivers, however with a prolonged reaction time of $10 \%{ }^{14}$.

Prasad, Hunter, and Hanley ${ }^{15}$ explored the driving experiences of disabled drivers using participants with a variety of diagnoses, including those with tetraplegia and paraplegia. Their study showed that about $80 \%$ of those who could drive had a $6.5 \%$ accident rate, which was considered to be the same as that of the general population ${ }^{15}$. However, they found that hand controls were initially difficult to master and those using the hand controls had the highest accident rate at initial stages ${ }^{15}$. This indicates that drivers using hand controls including drivers with $\mathrm{SCl}$ may initially experience difficulties with mastering new controls at the early stages of driving, or getting back to driving. By adequately compensating for the individual's impairments, fitness to drive abilities may be enhanced.

In our study, we used the Ecology of Human Performance (EHP) model, which offers a way of understanding how performance is tied to the context ${ }^{16,17}$. Ecology, in this model, is the interaction occurring between the person and his or her environment. The EHP model acknowledges that this interdependence between the person and the environment positively or negatively influences behaviour and occupational performance. The model also illustrates a relationship between the constructs of person, context, tasks, performance, and therapeutic intervention ${ }^{16,17}$.

Under the guiding principles of the Ecology of Human Performance (EHP) model ${ }^{17}$ the conceptual framework for this study, we studied the domains of the person (e.g. motor, sensory), the vehicle (e.g. hand controls), and the environment factors (e.g. driving in traffic). Recommendations in each of these domains may be incorporated as part of a driver rehabilitation programme to improve the fitness to drive abilities of this population.

\section{Driver rehabilitation services in South Africa}

An estimated 650 South Africans sustain spinal cord injuries every year $^{18}$. However, driver rehabilitation is not ordinarily included in South African rehabilitation programmes. In developed countries, for example in the United States of America (USA), occupational therapists who are certified driver rehabilitation specialists (OTCDRS) evaluate and intervene to improve fitness to drive among a variety of populations. Although experts, a driving rehabilitation researcher from Canada and a driver rehabilitation specialist from the USA, conducted workshops on driving assessments and interventions $(20 \mathrm{I}, 20 \mathrm{I}$ ) and on-going research mentoring at Stellenbosch University, no formal training exists for occupational therapists to become CDRS in South Africa. Additionally, in 20I I two centres for clinical driver rehabilitation were launched in Gauteng where occupational therapists and driving school instructors assess and train drivers with disabilities.

\section{Road safety in South Africa}

The South African motor vehicle injury mortality rate is 39.7 per 100000 citizens $^{19}$ - the worst in the world ${ }^{20}$. About 40 people are involved in fatal road traffic crashes per day, with an additional 20 being left permanently disabled ${ }^{20}$. Exposure to a high risk context can potentially impact the individual's own safety perceptions when driving, and the overall experience of driving.

\section{Rationale and significance of the study}

The impetus of this study derives from four fronts. First, an $\mathrm{SCl}$ is a life changing and disabling condition that impacts people differently, yielding unique sets of circumstances and needs for continued mobility and driving. Second, the driving experiences of persons with $\mathrm{SCl}$ are not well understood. Understanding these experiences can inform rehabilitation professionals on return to driving post-SCl. Third, poor road safety conditions in South Africa, coupled with limited driver rehabilitation services in the country create challenging conditions for individuals with a $\mathrm{SCl}$ who want to (return to) drive. Finally, driver rehabilitation is an emerging need in South Africa. Taken together, these issues indicate a need to understand individual perspectives of driving with $\mathrm{SCl}$ in South Africa to better inform clinical practice.

In South Africa, there are no published research studies to support driving and $\mathrm{SCl}$. Research conducted in developed countries shows some effort to explore the topic of driving with $\mathrm{SCl}$. However, articles that specifically included the experiences of driving with a $\mathrm{SCl}$ were quantitative in nature ${ }^{14,15}$.

This study examined the question: What are the lived experiences of drivers with $\mathrm{SCl}$ within the City of Cape Town Metropolitan area in South Africa.

\section{METHODOLOGY}

\section{Ethical considerations}

The Health Research Ethics Committee at Stellenbosch University approved this study. Each participant provided written informed consent before enrolling into the study.

\section{Research Design}

This study used a qualitative phenomenological design, inspired by Edmund Husserl $193 \mathrm{I}^{21}$. This approach seeks to know and comprehend the lived experiences of persons and their intentions within their contexts ${ }^{21}$. Crabtree and Miller ${ }^{21}$ stated that phenomenology is concerned with understanding the meaning of having certain experiences. Because the research was situated with the phenomenological tradition it focussed on personal accounts of the drivers with $\mathrm{SCl}$, uncovering their individual realities and lived experiences.

\section{Population and sampling procedures}

A purposive maximum variation sampling strategy with snowballing as a recruitment strategy was used. The study included I 4 persons with $\mathrm{SCl}$.

\section{Procedures}

The study population was accessed through a $\mathrm{SCl}$ organisation and a mobility devices company in the Western Cape. Those participants who responded positively to the invitation were recruited for study participation. Subsequent participants were recruited through use of the 'snowballing' technique which involved asking initial participants to recommend other potential participants. Interview arrangements were made telephonically or via e-mail, and intake occurred via a demographic profile form.

\section{Selection criteria}

Participants were recruited if they met the following criteria. They had to:

$*$ be 18 years or older, as the legal driving age of an automobile in the RSA is 18 years;

* have a medical diagnosis of $\mathrm{SCl}$ (any level), regardless of the cause;

* currently be driving a vehicle, or have attempted driving after the $\mathrm{SCl}$; and

$*$ be a resident in the City of Cape Town Metropolitan area.

Table I on page 57 displays the demographic characteristics of the participants $(\mathrm{N}=14,21.4 \%$ were female, while $78.6 \%$ were male), with diagnoses of paraplegia $(35.7 \%)$ or quadriplegia (64.3\%). The age range was 39 (24-63 yrs.). Road traffic crashes caused the spinal cord injury for nine $(64.3 \%)$ participants. The number of years driven before the injury ranged from nil to twenty 
Table I: Demographic characteristics of the study participants

\begin{tabular}{|c|c|c|c|c|c|c|c|}
\hline $\begin{array}{l}\text { "Name } \\
\text { (Pseudonym) }\end{array}$ & Sex & Age & Cause & $\begin{array}{l}\text { Resultant } \\
\text { disability }\end{array}$ & $\begin{array}{c}\text { Years of } \\
\text { driving before } \\
\text { SCI }\end{array}$ & $\begin{array}{l}\text { Years of } \\
\text { driving post- } \\
\text { SCl (in years) }\end{array}$ & $\begin{array}{c}\text { Type of } \\
\text { Occupation }\end{array}$ \\
\hline Brian & Male & 42 & $\begin{array}{l}\text { Road traffic } \\
\text { crash }\end{array}$ & Quadriplegia & 13 & 12 & $\begin{array}{c}\text { Full-time } \\
\text { employment }\end{array}$ \\
\hline James & Male & 30 & Gunshot & Paraplegia & None & $\mathrm{I}$ & Self-employed \\
\hline Jack & Male & 31 & $\begin{array}{l}\text { Road traffic } \\
\text { crash }\end{array}$ & Quadriplegia & 2 & 3 & $\begin{array}{c}\text { Full-time } \\
\text { employment }\end{array}$ \\
\hline Jiggs & Male & 63 & $\begin{array}{l}\text { Road traffic } \\
\text { crash }\end{array}$ & Paraplegia & 2 & 40 & $\begin{array}{c}\text { Full-time } \\
\text { employment }\end{array}$ \\
\hline Mercy & Female & 34 & $\begin{array}{l}\text { Road traffic } \\
\text { crash }\end{array}$ & Paraplegia & 6 & I year & $\begin{array}{c}\text { Full-time } \\
\text { employment }\end{array}$ \\
\hline Michael & Male & 39 & Diving & Quadriplegia & None & $\begin{array}{l}3 \text { (with } \\
\text { learner's) }\end{array}$ & Self-employed \\
\hline Nelson & Male & 57 & Diving & Quadriplegia & $\begin{array}{c}\text { About } 3 \text { years } \\
\text { legally }\end{array}$ & 38 & $\begin{array}{c}\text { Full-time } \\
\text { employment }\end{array}$ \\
\hline Olivia & Female & 50 & $\begin{array}{l}\text { Road traffic } \\
\text { crash }\end{array}$ & Quadriplegia & $\begin{array}{l}\text { None, but held } \\
\text { licence for two } \\
\text { years }\end{array}$ & 27 & $\begin{array}{l}\text { Part-time } \\
\text { employment }\end{array}$ \\
\hline Roxanne & Female & 45 & $\begin{array}{l}\text { Road traffic } \\
\text { crash }\end{array}$ & Quadriplegia & 17 & 9 & $\begin{array}{c}\text { Full-time } \\
\text { employment }\end{array}$ \\
\hline Schoemaker & Male & 43 & $\begin{array}{l}\text { Road traffic } \\
\text { crash }\end{array}$ & Quadriplegia & 20 & 9 & $\begin{array}{c}\text { Full-time } \\
\text { employment }\end{array}$ \\
\hline Shaddly & Male & 39 & $\begin{array}{l}\text { Road traffic } \\
\text { crash }\end{array}$ & Quadriplegia & 8 & 17 & $\begin{array}{c}\text { Full-time } \\
\text { employment }\end{array}$ \\
\hline Virgo & Male & 24 & $\begin{array}{l}\text { Road traffic } \\
\text { crash }\end{array}$ & Paraplegia & None & 2 & College Student \\
\hline Webster & Male & 43 & Gunshot & Paraplegia & None & 15 & $\begin{array}{c}\text { Full-time } \\
\text { employment }\end{array}$ \\
\hline Wiele & Male & 44 & Rugby & Quadriplegia & $\begin{array}{l}2 \text { years } \\
\text { (without } \\
\text { licence) }\end{array}$ & 25 & $\begin{array}{l}\text { Full-time } \\
\text { employment }\end{array}$ \\
\hline
\end{tabular}

and for after the injury from one to forty. Thirteen (of fourteen) participants were employed and one was a student. Of those employed, 10 (76.9\%) were full time employed, two (I5.4\%) were self-employed, while the remaining participant $(7.7 \%)$ was part-time employed.

\section{Research setting}

The research was conducted in the City of Cape Town Metropolitan area. The study participants and the researcher mutually agreed on a venue (e.g. work place) to conduct the interviews.

\section{Data collection}

Data collection occurred through face-to-face, semi-structured interviews, providing open-ended questions, probes and prompts ${ }^{21}$. Data collection was stopped when data saturation was reached for those participants who were still driving. As only one participant who ceased driving participated, data saturation could not be reached for those who attempted and ceased driving post $\mathrm{SCl}$. Interviews were audio taped and transcribed verbatim. The interviews were conducted in English. The least educated participant had a Grade II level of education, and all the participants were able to respond relevantly to questions posed without seeking additional explanation. Observations were also captured as part of field notes. Confidentiality was maintained by assigning pseudonyms to all participants. Hard copies of participant information was stored in a locked filing cabinet, while electronic files were stored in a password protected computer and server network. Participant information was only available to the first author, who conducted all interviews.

\section{Data analysis}

The analysis was an inductive and iterative process ${ }^{21}$. The Weft QDA electronic package Version I.0.I, developed by Alex Fenton in $2006^{22}$, was used for data analysis. Data analysis commenced with identification of meaningful units as codes. These were then sorted and organised to form categories ${ }^{18}$. The EHP model was then used to further conceptualise the findings according to person, vehicle, or environment factors. According to common themes that emerged, the data were reported via a narrative description.

\section{Trustworthiness}

Three techniques were employed to address credibility. First, data source triangulation ${ }^{23}$ entailed scrutinising different sources for convergence of information. The perspectives of 14 participants with different demographic characteristics (age, gender, duration of driving before and after sustaining $\mathrm{SCl}$, and level of injury) were obtained. Although most data were obtained from those who were still driving, the views of one individual who had temporarily quit driving were also obtained. Observations and field notes were also made. Second, peer debriefing was used. The first author shared analysed data with the second and third authors who provided feedback on themes that arose, and a consensus on the emergent themes was reached. Third, member checking was done. During this process provisional analysis and interpretations were taken back to the participants for their comments and validation. Member checks were conducted for eight (of fourteen) participants via Skype or telephone conversations. The remaining six participants were not reachable for member checking. 
Table II: Themes, sub-themes, categories, and sub-categories

\begin{tabular}{|c|c|}
\hline Six Major Themes & $\begin{array}{l}\text { Sub-themes } \\
\text { - Categories } \\
\text { ○ Sub-categories }\end{array}$ \\
\hline $\begin{array}{l}\text { Adjusting to limitations - Getting to know } \\
\text { your body in a different way }\end{array}$ & $\begin{array}{l}\text { Physical adjustments } \\
\text { - "Person" level } \\
\text { - "Vehicle" level } \\
\text { Psychological adjustments } \\
\text { - Accepting a new identity } \\
\text { - Experiences of fear } \\
\text { - Building confidence and getting used to hand controls }\end{array}$ \\
\hline Safety perceptions and influencing factors & $\begin{array}{l}\text { Pragmatism - Drive within your ability } \\
\text { - Physical limitations } \\
\text { - Participants' driving behaviours and habits } \\
\text { ○ Unfavourable environmental conditions } \\
\text { ○ Crime ridden areas } \\
\text { Poor road safety environment } \\
\circ \text { There is a lot of bad driving out there } \\
\circ \text { I drove without my licence for many years }\end{array}$ \\
\hline $\begin{array}{l}\text { The positive role of driving - When I } \\
\text { bought my car, then my life was changed }\end{array}$ & $\begin{array}{l}\text { Being isolated, stuck, and stranded (before driving) Independence, autonomy, freedom } \\
\text { Improved confidence, self-esteem, power } \\
\text { Occupational possibilities } \\
\text { - Employment and productivity } \\
\text { Social involvement / participation } \\
\text { - Role performance } \\
\text { - Sport and recreation } \\
\text { - Positive social contribution through assisting others } \\
\text { - Isolation eliminated } \\
\text { Inspiring and assisting others to drive }\end{array}$ \\
\hline Contextual features and supports & $\begin{array}{l}\text { Social support } \\
\text { - Emotional support } \\
\text { - Informational support } \\
\text { - Tangible support } \\
\text { Organisational support } \\
\text { Technological support }\end{array}$ \\
\hline Environmental barriers & $\begin{array}{l}\text { Limited driving schools accommodating drivers with disabilities } \\
\text { Procedures of buying adapted vehicles } \\
\text { Limited parking facilities } \\
\text { Challenges and inconsistencies at the traffic department } \\
\text { Limited personal finances }\end{array}$ \\
\hline $\begin{array}{l}\text { Inconsistent provision of rehabilitation } \\
\text { services }\end{array}$ & $\begin{array}{l}\text { Information dissemination } \\
\text { - Inadequate information provided } \\
\text { Driver evaluation } \\
\text { Driver training } \\
\text { Lack of recommendations and evaluation of hand controls }\end{array}$ \\
\hline
\end{tabular}

Techniques adding to trustworthiness were transferability, confirmability, and repeatability ${ }^{24}$. For transferability, a clear description of the study sample and the selection criteria were articulated. Details pertaining to the demographic characteristics of the participants to allow for reader comparison were provided. The South African context with respect to driving was also described.

By describing the study procedures and keeping the participant records for independent auditing confirmability was assured. The recorded and saved interviews were stored on a password coded universal serial bus (USB), both in audio and transcript format. The stages of the coding process illustrating the development of findings were also saved. Consistency was obtained through repeatability of procedures; i.e., using an interview guide with similar leading questions. Employing the above strategies culminated in trustworthiness.

\section{RESULTS}

Six themes, summarised in Table II, emerged from this study.

\section{Theme I: Adjusting to limitations}

All participants had to undergo physical and/or psychological adjustment in preparation for driving after sustaining the SCl. Physical adjustments included personal adjustments and vehicle adjustments. Personal adjustments were working to improve bodily functions (e.g. trunk stability, upper limb strength, and physical strength in general), adapting to a new way of driving with controls, finding alternative ways of transferring in and out of the vehicle, and managing the wheelchair. On the vehicle level, participants had to obtain modified vehicles to accommodate their physical limitations. Participants spoke about the need to make adjustments as follows:

Ah, it's quite an adjustment, because you need to get to know your body in a different way again. (Roxanne)

But then now l'm building up my strength even more, by going to gym and so I'll be even stronger to drive the car.... I don't want any assistance from anyone to help me or anything like that. (Michael)

Psychological adjustments included adjusting to changed identity, 
accepting disability, and experiencing fear and apprehension while on the road. Some of this was captured as follows:

Because, when I had the injury, I had to take some time to accept that this injury is also creating [in] me or causing me to be mobility impaired. (Brian)

\section{Theme 2: Safety perceptions and influencing factors}

This theme included the personal and environmental factors surrounding safety perceptions of drivers with $\mathrm{SCl}$. The participants were aware of their physical limitations.

Limitations mentioned included limited hand function, prolonged reaction time, impaired trunk stability, ageing as a driver with $\mathrm{SCl}$, and health related factors (e.g. effect of medication on driving). The participants developed safe driving habits and self-regulatory behaviours post-SCl, to mitigate the functional limitations. Most participants expressed that they had adapted to environmental features to regulate their driving. Environmental features mentioned ranged from unfavourable weather conditions, temporal aspects (e.g. time of day), to other unfavourable road conditions, including gravel and winding roads, for example:

I would start off by explaining that it is not the same as what it was before the spinal cord injury. And then also explain that I have to use less limbs but more concentration. (Brian)

I try and avoid [driving] at night, in general. But at night in the rain is my worst nightmare, and that I'll only do if I have to. I really prefer not to travel a lot at night. (Roxanne)

The participants also commented on the poor road safety conditions due to disregard of road traffic regulations by other drivers and inadequate enforcement of existing laws:

Yeah, man there is a lot of bad driving out there... (James)

Participants also highlighted poor monitoring of driving requirements by relevant officials:

... I drove without the licence for many years... (Jiggs)

The high crime rates in South Africa significantly influenced safety perceptions and driving habits for participants, as they felt they were more vulnerable and could be considered easy targets by criminals, compared to uninjured drivers. Hence, some participants avoided driving in townships associated with high crime rates.

I don't want to drive [in] the township ... because I always feel a bit vulnerable, like, I could be a victim and I can't even fight back... (James)

\section{Theme 3: The positive role of driving}

All participants testified that driving brought positive changes to their lives. Before they could drive post-SCl, the participants described their situations with words like 'isolated', 'stuck', and 'stranded'. Participants remarked that public transport was not wheelchair accessible and that public transportation systems in place to cater for physically disabled individuals were inadequate, expensive, and inconvenient.

... it [driving] was so significant to me because I was stranded at first. After the injury I was always at home ... I couldn't go to school. I applied for Dial-a-Ride; they took forever to process the application... (James)

Benefits of driving mentioned by participants included increased occupational possibilities; enhanced participation in sporting and recreational activities; enhanced role performance; improved confidence, self-esteem, and power; eliminating isolation; and improved independence, autonomy, and freedom. Participants highlighted:

I would say, giving me my independence back ... and not having to depend on others. (Shaddly)

The ability to drive has given me... an inch over the rest of my family ... Where I would have ... been seen as someone who needs assistance, I can assist now with my ability to drive. (Brian)
As a result of the positive changes brought by driving, most participants inspired others by engaging in motivational speaking, conducting demonstrations at rehabilitation centres, availing their vehicles for use by others with $\mathrm{SCl}$, or practically teaching others to drive.

\section{Theme 4: Contextual features and support}

This theme refers to those factors within the participants' context that were perceived to support the resumption of driving post-SCl. The sources of support mentioned included social support, organisational support, and technological support. Three main types of social support were emotional, informational and tangible support. Examples of emotional social support mentioned are:

I will say my family, you know, they always [have] my back, yah. When I always slow down... they always give me that motivation. (James)

Examples of tangible support highlighted by participants included support obtained through organisations working with persons with $\mathrm{SCl}$. One participant used a vehicle from one of the organisations working with persons with $\mathrm{SCl}$ for his driving lessons:

The [organisation] has a vehicle with the hand controls ... I used their car to do my driving lessons. (Schoemaker)

From interacting with friends and other drivers with disabilities, participants gained information about driving schools, vehicle conversions, community resources, and the experiences of driving with $\mathrm{SCl}$.

.. but there was this guy from P.E. [Port Elizabeth] He is also a SCl. $\mathrm{He}$ [also drives] a car. So he told me the people who can teach me how to drive... (James)

\section{Theme 5: Environmental barriers}

This theme identified contextual features that negatively affected return to driving post-SCl. These included a limited number of driving schools accommodating drivers with physical disabilities; limited parking facilities for physically disabled drivers; challenges and inconsistencies at the traffic department; limited personal finances; and challenges when buying adapted vehicles. Below are examples of comments made by participants regarding challenges encountered when driving post-SCl:

... the big challenge was that I [didn't] have a licence. I kept obtaining the learners, I drove my car to the guys who [had] the driving schools. So they didn't help me because they [said] they didn't know how to drive my car, the converted car. So it's so difficult for them to teach me how to drive because they used to use the manuals, you see. That was a big challenge that I [had]. So, mind, count from 1998 ... I've got a licence by 2004. (Webster)

I think the other challenge is basically ... finding a vehicle ... that is well equipped for you ... (Schoemaker)

If some of [those] laws were relaxed, then we would have been able to import a car that is already adapted. (Brian)

Our traffic authorities are not suitably educated when it comes to dealing with disabled drivers ... (Shaddly)

\section{Theme 6: Lack of provision of driver rehabilitation services}

The involvement of rehabilitation professionals in providing information, conducting driver evaluations and driver training were experienced by participants as lacking during return to driving post-SCl.

The OT... gave me the contact numbers for the guys who converted the cars. But ... he didn't know anyone who can teach me how to drive, yah. (Webster)

I can only thank the professionals while I was at hospital, but while I was outside hospital it was me and my family. (James)

There was no one, eh, involved. Yah, because to be honest, the occupational therapists ... don't have an idea, you know, how to do it, or what's the best. (Michael) 
Clear communication of assessment finding by rehabilitation professionals to people who are responsible for making vehicle adaptations was stressed by one participant.

... sometimes also you go to the people that [do] the adaptions, they don't know ... how to test your strengths ... So, eventually by the therapist getting that information, they can make an informed decision ... (Michael)

\section{DISCUSSION}

\section{Demographics of participants}

The demographic characteristics of participants in this study correlated to the typical demographic trends reported in driving and $\mathrm{SCl}$ literature; considering that $\mathrm{SCl}$ is a disability that is relatively common among young males ${ }^{25}$, as the current study population was relatively young with an average age of 42 years. The male to female ratio of the study participants was 3.7:I, which is similar to the reported global ratio of 3.8: $\left.\right|^{25}$. Road traffic crashes were the leading cause of $\mathrm{SCl}$ among the participants, and road traffic incidents are rated the second largest cause of $\mathrm{SCl}$ in South Africa ${ }^{26}$.

\section{Adjusting to physical limitations}

The participants reported that they had to make personal and vehicular adjustments to resume driving post-SCI. Similar to a study in Japan' the majority of the participants reported having experienced initial difficulties mastering the hand controls, but these challenges dwindled with experience. Occupational therapists - even without particular training in driving assessment and rehabilitation - are positioned to be able to assist with the impact of body system limitation on occupational performance. Specific training in the driver rehabilitation area may improve targeted service delivery to enhance aspects of fitness to drive for clients with $\mathrm{SCl}$.

Participants generally felt confident with driving at the time of conducting the interviews. However, persistent feelings of fear were noted among participants whose $\mathrm{SCl}$ was due to road traffic accidents. This may indicate a need for psychological intervention to better prepare such drivers for return to driving.

The participants' struggle with adjusting to a new identity post$\mathrm{SCl}$ may be attributed to the loss of pre-injury roles ${ }^{27}$. Considering the positive role of driving in promoting independence and role fulfilment, driving rehabilitation may facilitate construction of a positive self-identity following an SCI.

\section{Safety perceptions and influencing factors}

The participants demonstrated an awareness of challenges related to their physical disability when driving. They identified negative impacts of ageing on a driver post-SCl and suggested a need for continued follow-up for appropriate recommendations (e.g. lighter wheelchairs for ageing drivers with $\mathrm{SCl}$ ). Such recommendations may minimise premature driving cessation.

Participants who experienced fatigue from frequent braking and acceleration ${ }^{28}$ may benefit from alternative hand controls. For instance, the use of adaptive cruise control, instead of separate hand controls, may enhance adequate braking or accelerating ${ }^{28}$. Other physical limitations mentioned by the study participants, include prolonged reaction time ${ }^{14}$ and impaired trunk stability ${ }^{29}$. Understanding the various physical limitations experienced by drivers with $\mathrm{SCl}$ coupled with knowledge of vehicle modifications may inform better driving rehabilitation recommendations.

\section{Participants' driving behaviours and driving habits}

Being aware of their physical limitations enabled the study participants to adopt safe driving habits and employ self-regulatory strategies. Strategies and habits included avoiding driving in crime-ridden areas, leaving longer following distances, driving more cautiously, familiarising themselves with unfamiliar routes, as well as avoiding driving at night, during peak hour periods, and/or in bad weather conditions. Such strategies are also evident in older driver studies ${ }^{30}$.

\section{Poor road safety environment}

Apart from functional limitations due to $\mathrm{SCl}$, the majority of the participants in this study raised concerns about the poor road environment in South Africa, which further compromised their safety. These factors included human factors (e.g. negligence) $)^{31}$ and poor enforcement of existing laws ${ }^{32}$ (e.g. lack of screening of medically at-risk drivers, inadequate licencing and monitoring). This finding indicated that intervention programmes to improve fitness to drive must be supported by strategies targeting the poor road conditions in the South African society, such as improved monitoring of drivers to ensure they have appropriate licenses, and enhanced enforcement of existing laws. Thus, a collaborative effort between the health sector, traffic department, and local authorities could potentially contribute to improved road safety conditions.

The positive role of driving with spinal cord injury The participants indicated that before resuming driving they were isolated and restricted to their home environments, similar to findings from older driver studies " . Interestingly, the lack of accessible public transportation motivated the participants to return to driving. Nevertheless, given the benefits of driving, its role for those with a $\mathrm{SCl}$, such as improved independence, enhanced occupational possibilities, ability to engage in leisure and recreational activities, and improved self-esteem and self-confidence, has been expressed by several participants in this study.

\section{Contextual features and support}

The participants in this study received emotional, informational, and instrumental support from organisations directly involved with persons with disabilities and social environment (family, friends, and other drivers with $\mathrm{SCl}$ ) when returning to driving post-SCl. Furthermore, the extent to which the participants in this study expressed a desire to assist other persons with $\mathrm{SCl}$ to drive was unexpected. This finding indicates that other drivers with $\mathrm{SCl}$ are a potential support system whom rehabilitation professionals can involve during driver rehabilitation. Likewise, better support, e.g., financial support for obtaining adapted vehicles used for driver training, can be a significant starting point when promoting driving post-SCl.

\section{Environmental barriers}

The study participants mentioned barriers to driving post-SCI in South Africa. As a result, the following needs were expressed by the participants: a need for financial assistance from the government towards obtaining and modifying vehicles as practiced in Sweden ${ }^{33}$; a need for improved monitoring of reserved parking spaces for drivers with disabilities (e.g. through introducing stiff penalties for violating disabled parking facilities); a need to provide standard guidelines for traffic officials when assessing people with physical disabilities including SCl; and a need for review of the current procedures of purchasing an adapted vehicle. These suggestions hold promising approaches for enhancing services for people with $\mathrm{SCl}$, and create plausible practice, policy and research opportunities.

\section{Inconsistent provision of driver rehabilitation services}

The participants highlighted a lack of rehabilitation professionals' involvement in providing information, driver evaluation, driver training, and recommendation of hand controls - findings which are consistent with the $\mathrm{SCl}$ literature ${ }^{33,34}$. Participants confirmed that there is a need for rehabilitation professionals to evaluate individuals and make appropriate recommendations that may adequately compensate for individuals' limitations. Thus, occupational therapy practitioners are encouraged to consider implementing driver rehabilitation strategies into the management of $\mathrm{SCl}$.

\section{Study limitations}

Only eight (of 14) participants were reachable for member checking. Only one participant who had stopped driving participated in the study, limited in-depth data on nuances of driving cessation 
following a SCl was therefore obtained. The first author was not fluently conversant in two of the indigenous languages of the natives of Cape Town (Afrikaans and Xhosa). Using only the English language during interviews may have affected the participants' ability to express their views.

\section{Recommendations for practice, policy and research}

Overall, occupational therapists in South Africa do not have adequate training in the field of driver rehabilitation. Given the significance of the ability to drive, as highlighted by participants in this study, driving specific education is recommended to support occupational therapy practices. Educational bodies providing entry level programmes or continuing professional development may consider including training in driver rehabilitation. Likewise, occupational therapists may also consider pursuing an active partnership with vehicle modification companies. As such, the occupational therapists may prescribe, monitor and evaluate the installed vehicle modifications of individuals with a SCl.

Adequate psychological support and research to investigate the presence of symptoms of post-traumatic stress disorder is indicated for drivers whose $\mathrm{SCl}$ was due to a road traffic crash. Therefore, a plausible opportunity exists for occupational therapists to screen for such individuals and make appropriate referrals for psychotherapeutic intervention during rehabilitation.

Trained occupational therapists may also assume an educational role for traffic department officials and driving school instructors, pertaining to the driving needs of individuals with physical disabilities. This study suggests a critical need for developing and implementing standard guidelines for driving assessors evaluating persons with $\mathrm{SCl}$.

Occupational therapists are encouraged to assume advocacy and mediation roles on a broader societal level in order to minimise the various environmental barriers (e.g., challenges with procedures of purchasing an adapted vehicle) for return to driving post-SCl. Moreover, the findings indicate a need for improved monitoring and enforcement of existing laws. For example, regulation and enforcement are necessary to ensure that all drivers on the road hold valid and appropriate licences, including those with physical disabilities.

To further understand the perceptions of participants who underwent driving cessation post- $\mathrm{SCl}$, a follow-up qualitative research study is recommended. Focused studies can explore each of the emergent themes to further clarify the concerns of the participants. Repetition of this study, for example in a different province, can contribute to an enhanced understanding of the factors promoting and/or hindering driving post-SCl in South Africa. Likewise, to explore the educational needs of occupational therapists, a survey may be conducted to investigate their current practices and approaches towards driver rehabilitation.

\section{CONCLUSION}

This study is novel in that it is the first in South Africa to explore the lived experiences of drivers with a $\mathrm{SCl}$. It presents a fundamental step towards laying a foundation for investigating medically at-risk drivers. It also provides an in-depth account of the driving experiences of drivers with $\mathrm{SCl}$ from an occupational therapy perspective and contributes to understanding the EHP model in a driving related study. Through the expressions of the participants, the role for occupational therapists in driving rehabilitation post-SCl is critical, yet lacking. Finally, the study elucidated the needs, barriers, and opportunities for driving with a $\mathrm{SCl}$, which contributes first-time knowledge to the South African occupational therapy literature.

\section{ACKNOWLEDGEMENTS}

Preparation of this manuscript was funded by the Canada-Africa Research Exchange Grant (PI: Dr. Sherrilene Classen, Co-PI Dr. Lana Van Niekerk).

\section{REFERENCES}

I. Classen S, Dickerson AE, Justiss MD. Occupational therapy driving evaluation: Using evidence-based screening and assessment tools. In: McGuire MJ \& Schold-Davis E, editors. Driving and community mobility: Occupational therapy across the lifespan. Bethesda MD: AOTA Press; 2012: 221-277.

2. Campagnolo DI. Spinal cord injury- Definition, epidemiology, pathophysiology [Online] 20II [cited 201I, December 14]; Available from: http://emedicine.medscape.com/article/322480-overview.

3. World Health Organisation. International Classification of Functioning, Disability and Health [Online] 200I [Cited 2012, April 23]; Available from: www.disabilitaincifre.it/documenti/ICF_I8.pdf.

4. Brouwer WH, Ponds RWHM. Driving competence in older persons. Disability and Rehabilitation, 1994; 16(3): 149-16I.

5. Stav WB, Pierce S, Wheatley CJ, Davis ES. American Occupational Therapy Association Statements: Driving and community mobility. The American Journal of Occupational Therapy, 2005; 59(6): 666-670.

6. Hunt L. (1993). Evaluation and retraining programs for older drivers. Clinics in Geriatric Medicine, 1993; 9(2): 439-449.

7. Cox JL, Fox MD, Irwin L. Driving and the elderly: A review of the literature. Physical \& Occupational Therapy in Geriatrics, 1989; 7(I-2): 7-12.

8. Cobb RW, Coughlin JF. Regulating older drivers: How are the states coping? Journal of Aging and Social Policy, 1998; 9(4): 7I-87.

9. Kiyono Y, Hashizume C, Matsui N, Ohtsuka K, Takaoka K. Cardriving abilities of people with tetraplegia. Archives of Physical Medicine and Rehabilitation, 2001; 82(10): 1389-1392.

10. Dias de Faria M. The purchase of adapted cars for people with motor disabilities: Netnography of the motivations and transformations in the lives of consumers. Rio de Janeiro: UFRJ/ COPPEAD; 2012.

I I. Marotolli RA, Mendes de Leon CF, Glass TA, Williams CS, Cooney Jr WS, Berkman LF. Consequences of driving cessation: Decreased out-of-home activity Levels. The Journals of Gerontology Series B: Psychological Sciences and Social Sciences, 2000; 55(6): S334-S340.

12. Marottoli RA, Mendes de Leon CF, Glass TA et al. Driving cessation and increased depressive symptoms: Prospective evidence from the New Haven EPESE. Journal of American Geriatric Society, 1997; 45(2): 202-206.

13. Peters B. Driving performance and workload assessment of drivers with tetraplegia: an adaptation evaluation framework. Journal of Rehabilitation Research and Development, 2001; 38(2): 21 5-224.

14. Michon JA. A critical view of driver behaviour models: what do we know, what should we do? In: Evans EL, Schwing R. Human behavior and traffic safety. New York: Plenum Press; 1985: 485-520.

15. Prasad RS, Hunter J, Hanley J. Driving experiences of disabled drivers. Clinical Rehabilitation, 2006; 20(5): 445-450.

16. Dunn W, Brown C, McGuigan A. The Ecology of Human Performance: A Framework for Considering the Effect of Context. The American Journal of Occupational Therapy, 1994; 48(7): 595-607.

17. Law M, Cooper BA, Strong S, Stewart D, Rigby P, Letts L. Theoretical contexts for the practice of occupational therapy. In: Christiansen C, Baum C, editors. Enabling function and well-being. 2nd ed. Thorofare: Slack incorporated; 1997: 74-102.

18. The Western Cape Association of People with Disabilities. Buckle up: We don't want new members [Online] [cited 2012, October I6]; Available from: http://www.apd-wc.org.za/images/downloads/ APD_BuckleUpCampaign.pdf.

19. Norman R, Matzopoulos R, Groenewald P, Bradshawl D. The high burden of injuries in South Africa. World Health Organization Bulletin, 2007; 85(9): 695-702.

20. Decade of Action and Arrive Alive. National road safety strategy 20I I-2020 [Online] [cited 2013, February 2I]; Available from: http://www.arrivealive.co.za/documents/Road\%20Safety\%20 Strategy\%20for\%20South\%20Africa\%2020 I I.pdf.

21. Crabtree BF, Miller WL. Doing qualitative research. Vol 3. USA: Sage publications; 1992

22. Alex Fenton. Weft QDA User's manual. [Online] 2006 [cited 20I4, February 12]. Available from: http://www.pressure.to/qda/doc/ weft_manual-en.pdf.

23. DePoy E, Gitlin LN. Introduction to research: Multiple strategy for health and human services. Mosby: St Louis; 1994.

24. Van der Walt M, Redivo V, Bredenhann M, Essa F, Eloff N, MostertWentsel K. Community Physiotherapists Experiences and Ex- 
pectations when doing Compulsory Service: A Qualitative Study. [Unpublished research study]. Pretoria: University of Pretoria; 2009.

25. Wyndaele M, Wyndaele JJ. Incidence, prevalence and epidemiology of spinal cord injury: what learns a worldwide literature survey? Spinal Cord, 2006; 44(9): 523-9.

26. Hart C, Williams E. Epidemiology of spinal cord injuries: a reflection of changes in South African Society. Paraplegia, 1994; 32: 709-7I4.

27. Wiechman SA, Williams J. Relation of athletic identity to injury and mood disturbance. Journal of Sport Behaviour, 1997; 20: 199-211.

28. Peters B. Adaptation evaluation - An adaptive cruise control (ACC) system used by drivers with lower limb disabilities. International Association of Traffic and Safety Sciences Research, 200 I; 25(I): 5 I-60.

29. Pansegrouw H. Automobility: The comprehensive guide to motoring for people with mobility impairments. Florida: Word for Word Media; $201 \mathrm{I}$.

30. Elliott $D$, Elliott $B$, Lysaght $A$. Older driver risks and countermeasures: Source Book. Australia: Australian Government Publishing Services; 1996.

31. Vogel L, Bester CJ. A relationship between accident types and causes. Proceedings of the $24^{\text {th }}$ Southern African Transport Conference; 2005 July I I-I 3; Pretoria, South Africa. Pretoria: Document Transformation Technologies cc.

32. Norman R, Matzopoulos R, Groenewald P, Bradshawl D. The high burden of injuries in South Africa. World Health Organization Bulletin, 2007; 85(9): 695-702.

33. Lovgren A, Ryd C,Falkmer T, Peters B. The role of occupational therapists in the automobility process. Paper presented at: Transed 2007. Benchmarking, evaluation and vision for the Future, I/th International Conference on Mobility and Transport for Elderly and Disabled Persons; 2007 June 18-22; Montreal, Canada.

34. Njoki E, Frantz J, Mpofu R. 2007a. Health promotion needs of youth with a spinal cord injury in South Africa. Disability and Rehabilitation, 2007a; 29(6): 465-472.

\section{Corresponding Author}

Lucia Mtetwa

mtetwa.lucia@gmail.com 